\title{
Crocin has pharmacological effects against the pathological behavior of colon cancer cells by interacting with the STAT3 signaling pathway
}

\author{
JUN WANG ${ }^{1}$, YUPEI KE ${ }^{1}$ and TAO SHU ${ }^{2}$ \\ ${ }^{1}$ Graduate School, Jinzhou Medical University; ${ }^{2}$ Department of Anorectal Surgery, \\ The Third Affiliated Hospital of Jinzhou Medical University, Jinzhou, Liaoning 121000, P.R. China
}

Received December 6, 2018; Accepted October 7, 2019

DOI: $10.3892 /$ etm.2019.8329

\begin{abstract}
The aim of the present study was to investigate changes in proliferation, apoptosis, inflammation and chemokine release of colon cancer cells after treatment with crocin, as well as to investigate the signaling pathway that is regulated by crocin. The inhibition rates of different doses of crocin on the proliferation of HCT116 cells were measured by MTT assay. The $\mathrm{IC}_{50}$ was calculated from the inhibition rates at $48 \mathrm{~h}$. Proliferation curves of HCT116 cells were plotted after treatment with $271.18 \mu \mathrm{M}$ (high-dose group) or $135.6 \mu \mathrm{M}$ (low-dose group) crocin. Flow cytometry and Hoechst 33342/propidium iodide double staining were used for detecting apoptosis. ELISA was used to measure the levels of macrophage inflammatory protein 2 , interleukin (IL)-8, monocyte chemoattractant protein 1 , tumor necrosis factor- $\alpha$, IL- 6 and IL-1 $\beta$ in the supernatant from cultured HCT116 cells following both high- and low-dose crocin treatment. Phosphorylated (P)-STAT3/STAT3 in HCT116 cells were measured by western blotting. Crocin inhibited the proliferation of HCT116 cells in a dose-dependent manner and the high-dose treatment with crocin resulted in a lower rate of proliferation. Additionally, crocin increased the apoptosis of HCT116 cells and the high-dose treatment with crocin led to a higher level of apoptosis. Notably, crocin decreased the secretion of chemokines and inflammatory factors from HCT116 cells and the high-dose treatment with crocin caused the greatest reduction in secretion of the factors. Crocin reduced the ratio of P-STAT3/STAT3, and thereby reduced the release of cytokines. The present study demonstrated that crocin may have pharmacological effects against the pathological
\end{abstract}

Correspondence to: Dr Tao Shu, Department of Anorectal Surgery, The Third Affiliated Hospital of Jinzhou Medical University, 2-Section 5 Heping Road, Jinzhou, Liaoning 121000, P.R. China E-mail: shutaojinzhou@126.com

Key words: colon cancer, chemokines, crocin, STAT3, inflammatory factors behavior of colon cancer cells, and its mechanism of action may be related to the STAT3 signaling pathway.

\section{Introduction}

Crocin is an effective water-soluble active monomer extracted from Crocus sativus, a plant that is used in traditional Chinese medicine (1). It is reported that crocin has a number of beneficial properties, such as for the treatment of myocardial ischemia and hypoxia; improving behavior and cognition; and anti-lipid peroxidation, anti-atherosclerosis and antitumor effects (1-4). Proteoglycans extracted from $C$. sativus can promote the activity of macrophages and promotes immune regulation and invasion resistance (5). Crocin can effectively inhibit the activity of free radicals and xanthine oxidase, thereby acting as an antioxidant (6). In addition, crocin has anti-inflammatory effects and has been used as an adjuvant for various inflammatory diseases $(7,8)$.

The incidence of colorectal cancer has increased in China, with only lung cancer and gastric cancer showing higher incidences (9). Early colorectal cancer lacks clear and typical symptoms and most patients with colorectal cancer are already at an advanced stage and at risk of metastasis upon diagnosis. As such, the optimal point for beginning treatment has already passed and the prognosis is not as favorable (10). Inflammation is involved in the occurrence and development of colon cancer (11). For example, interleukin (IL)-1 $\beta$, IL-6 and tumor necrosis factor (TNF)- $\alpha$ are involved in all aspects of colon cancer $(12,13)$. However, the anticancer and anti-inflammatory functions of crocin in colon cancer cells have not been investigated.

In the present study, proliferation and apoptosis of colon cancer cells, inflammatory responses in colon cancer cells, as well as chemokine release from colon cancer cells was investigated following treatment with crocin. The signaling pathways that are regulated by crocin were also examined.

\section{Materials and methods}

Cells. HCT116 cells (The Cell Bank of Type Culture Collection of the Chinese Academy of Sciences) were cultured in McCoy's 5A (Modified) Medium (16600082; Thermo Fisher 
Scientific, Inc.) supplemented with 10\% FBS (Thermo Fisher Scientific, Inc.) at $37^{\circ} \mathrm{C}$ and $5 \% \mathrm{CO}_{2}$. Prior to western blot analysis, HCT116 cells were treated with Stattic (HY-13818; MedChemExpress), according to the manufacturer's instructions, to inhibit the activity of the STAT3 signaling pathway.

MTT assay. HCT116 cells in the logarithmic growth phase were digested, resuspended at a density of $2 \times 10^{4}$ cells $/ \mathrm{ml}$ and seeded into 96 -well plates at $37^{\circ} \mathrm{C}$ and $5 \% \mathrm{CO}_{2}$. To test the effect of crocin on the proliferation of HCT116 cells, cells were treated with either a high or low dose of crocin. The cells in the high-dose group were treated with $271.18 \mu \mathrm{M}$ crocin and those in the low-dose group were treated with $135.6 \mu \mathrm{M}$ crocin at $37^{\circ} \mathrm{C}$ for 24,48 or $72 \mathrm{~h}$. To these the inhibitory rate of crocin, after adhesion of the cells to the surface of the plate at $37^{\circ} \mathrm{C}$ for $8 \mathrm{~h}$, the medium was replaced with McCoy's 5A (Modified) Medium containing $10 \%$ FBS and varying concentrations of crocin (50, 100, 200, 400, 800 and 1,600 $\mu \mathrm{M}$; ES-0329; Extrasynthese) following previous studies $(14,15)$. The control group was cultured in medium without drugs. Each concentration was examined in triplicate. After culture at $37^{\circ} \mathrm{C}$ and $5 \%$ $\mathrm{CO}_{2}$ for $24,48,72,96,120$ or $144 \mathrm{~h}$, the medium was replaced with serum-free medium. In the dark, $5 \mathrm{mg} / \mathrm{ml}$ MTT solution (20 $\mu \mathrm{l}$ ) was added onto the cells which were then incubated at $37^{\circ} \mathrm{C}$ for $4 \mathrm{~h}$. Subsequently, the medium was discarded, and DMSO $(150 \mu \mathrm{l})$ was added into each well before shaking at $37^{\circ} \mathrm{C}$ in the dark for $5 \mathrm{~min}$. Then, the absorbance was read at $570 \mathrm{~nm}$ using a microplate reader (DG5033A; Nanjing Huadong Electronics Co., Ltd.), and this reflected cell viability or number. The following formula was used: Inhibition rate of drugs on cell proliferation $(\%)=(1-$ absorbance of drug group/absorbance of control group) x $100 \%$. Growth curves were plotted using time $(\mathrm{h})$ as the $\mathrm{x}$-axis, and absorbance as the $\mathrm{y}$-axis. The $\mathrm{IC}_{50}$ was calculated from inhibitory rates at $48 \mathrm{~h}$.

Transwell assay. To test invasion ability, Matrigel ${ }^{\circledR}$ (BD Biosciences) was thawed at $4^{\circ} \mathrm{C}$ overnight and diluted with serum-free medium (dilution, 1:2). The mixture $(50 \mu \mathrm{l})$ was evenly applied to the upper chambers of Transwell plates (Merck KGaA) on ice and incubated at $37^{\circ} \mathrm{C}$ for $1 \mathrm{~h}$ for solidification. HCT116 cells $\left(2 \times 10^{5}\right.$ cells/well) from the control group or the crocin treatment groups were seeded into the upper chamber containing 200- $\mu$ l serum free medium at $37^{\circ} \mathrm{C}$. A total of $500 \mu 1$ medium supplemented with $10 \%$ FBS was added into the lower chamber. After $24 \mathrm{~h}$ of incubation at $37^{\circ} \mathrm{C}$, the chamber was removed and the cells in the upper chamber were wiped off. After being fixed with $4 \%$ formaldehyde at room temperature for $10 \mathrm{~min}$, the membrane was stained with Giemsa at room temperature for $15 \mathrm{~min}$ and observed using a light microscope (in 5 random fields (magnification, x200). The number of invading cells was counted to evaluate the cell invasion ability.

Hoechst 33342/propidium iodide (PI) double staining. After being treated with crocin for $24 \mathrm{~h}, \mathrm{HCT} 116$ cells were subjected with Hoechst 33342/PI double staining (cat. no. C1056; Beyotime Institute of Biotechnology). The cells were first washed with PBS twice, and $5 \mu 1$ Hoechst stain and $5 \mu \mathrm{l}$ PI stain were added onto the cells before incubating at $4^{\circ} \mathrm{C}$ for 20-30 min. After staining, the cells were washed with PBS twice before observing red (Hoechst) and blue (PI) fluorescence under a fluorescence microscope (Axio Scope A1; Carl Zeiss AG) at a magnification of x100.

Flow cytometry. Cells $\left(1 \times 10^{6}\right)$ in each group were washed with pre-cooled phosphate-buffered saline twice and subjected to flow cytometry using Annexin V-FITC/PI Apoptosis Detection kit (A211-01/02; Vazyme) following the manufacturer's protocol to detect cell apoptosis. Cells with Annexin V-positive values were considered early apoptotic cells, those with PI-positive values were considered necrotic, and those with double positive values were considered late apoptotic.

ELISA. Cell supernatant was centrifuged at $3,000 \times \mathrm{g}$ and $4^{\circ} \mathrm{C}$ for $10 \mathrm{~min}$ to eliminate cell debris. IL-6 (cat. no. ab46027), TNF- $\alpha$ (cat.no. ab181421), IL-1 $\beta$ (cat. no. ab46052), macrophage inflammatory protein (MIP)-2 (cat. no. ab184862), monocyte chemoattractant protein (MCP)-1 (cat. no. ab100586), and IL-8 (cat. no. ab46032) ELISA kits (Abcam) were used to determine the concentrations of respective proteins in the cell supernatant. In 96-well microplates, standards (50 $\mu \mathrm{l})$ and samples (10 $\mu \mathrm{l}$ serum and $40 \mu \mathrm{l}$ diluent) were added into predefined wells, while blank wells were left empty. In the wells for standards and samples, horseradish peroxidase-labelled conjugates $(100 \mu \mathrm{l})$ were added before sealing the plates for incubation at $37^{\circ} \mathrm{C}$ for $1 \mathrm{~h}$. After washing the plates five times, substrates A $(50 \mu \mathrm{l})$ and $\mathrm{B}(50 \mu \mathrm{l})$ were added into each well. After incubation at $37^{\circ} \mathrm{C}$ for $15 \mathrm{~min}$, stop solution $(50 \mu \mathrm{l})$ was added into each well, and absorbance of each well was measured at $450 \mathrm{~nm}$ using a microplate reader within $15 \mathrm{~min}$.

Reverse transcription-quantitative PCR (RT-qPCR). Cells $\left(3 \times 10^{6}\right)$ were directly lysed with $1 \mathrm{ml}$ TRIzol reagent (Invitrogen; Thermo Fisher Scientific, Inc.). Total RNA was extracted using phenol chloroform method. The concentration and quality of RNA was measured using ultraviolet spectrophotometry (NanoDrop ${ }^{\mathrm{TM}}$ ND2000; Thermo Fisher Scientific, Inc.). Subsequently, cDNA was obtained by RT from $1 \mu \mathrm{g}$ RNA and stored at $-20^{\circ} \mathrm{C}$. RT of mRNA was performed using TIANScript II cDNA First Strand Synthesis kit (Tiangen Biotech Co., Ltd.) according to the manufacturer's protocol. SuperReal PreMix (SYBR-Green) kit (Tiangen Biotech Co., Ltd.) was used to detect mRNA expression, using GAPDH as an internal reference. The reaction system $(20 \mu \mathrm{l})$ was composed of $10 \mu \mathrm{l} \mathrm{SYBR}$ Premix EXTaq, $0.5 \mu \mathrm{l}$ forward primer (STAT3, 5'-GGAGGAGGCATTCGGAAAG-3'; $\beta$-actin, 5'-AACGGC TCCGGCATGTGCAA-3'), $0.5 \mu 1$ reverse primer (STAT3, 5'-TCGTTGGTGTCACACAGAT-3'; $\beta$-actin, 5'-CTTCTG

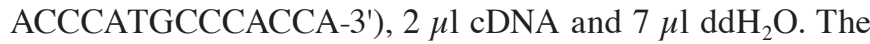
following thermocycling conditions were used: Initial denaturation at $95^{\circ} \mathrm{C}$ for $5 \mathrm{~min} ; 46$ cycles of denaturation at $95^{\circ} \mathrm{C}$ for $20 \mathrm{sec}$ and annealing at $55^{\circ} \mathrm{C}$ for $20 \mathrm{sec}$; and a final extension at $72^{\circ} \mathrm{C}$ for $30 \mathrm{sec}$ (iQ5 system; Bio-Rad Laboratories, Inc.). The $2^{-\triangle \Delta \mathrm{Cq}}$ method was used to calculate the relative expression of target mRNA against GAPDH (16). Each sample was tested in triplicate.

Western blotting. Before lysis, cells $\left(1 \times 10^{6}\right)$ were trypsinized and collected. Then, the cells were lysed with precooled 

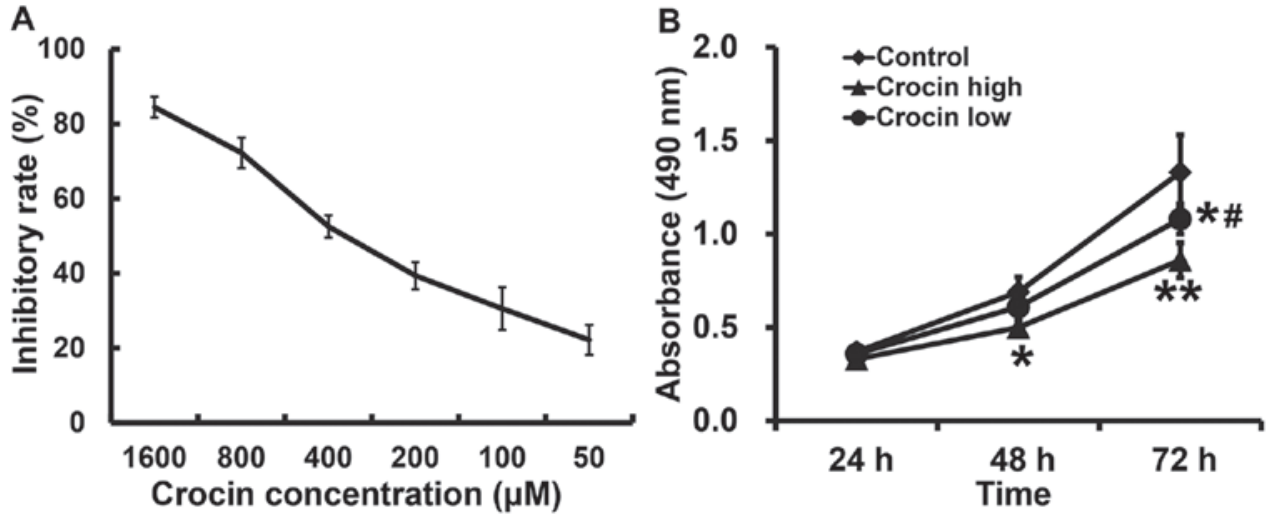

Figure 1. Effect of crocin on the proliferation of HCT116 cells. (A) Inhibition rate curve used for the determination of $\mathrm{IC}_{50}$ of crocin on the proliferation of HCT116 cells. The cells were treated with 50,100, 200, 400, 800 or 1,600 $\mu \mathrm{M}$ crocin for $48 \mathrm{~h}$ before the MTT assay. (B) Proliferation of HCT116 cells treated with crocin high-dose $(271.18 \mu \mathrm{M})$ or low-dose $(135.6 \mu \mathrm{M})$ for 24,48 or $72 \mathrm{~h}$. Absorbance was recorded at $490 \mathrm{~nm}$. ${ }^{*} \mathrm{P}<0.05$, ${ }^{* *} \mathrm{P}<0.01$ vs. the control group; ${ }^{\#} \mathrm{P}<0.05$ vs. crocin high.

RIPA lysis buffer $(600 \mu \mathrm{l} ; 50 \mathrm{mM}$ Tris-base, $1 \mathrm{mM}$ EDTA, $150 \mathrm{mM} \mathrm{NaCl}, 0.1 \%$ sodium dodecyl sulfate, $1 \%$ Triton $\mathrm{X}-100$, $1 \%$ sodium deoxycholate; Beyotime Institute of Biotechnology) for $30 \mathrm{~min}$ on ice. The mixture was centrifuged at $11,000 \mathrm{x} \mathrm{g}$ and $4^{\circ} \mathrm{C}$ for $10 \mathrm{~min}$. The concentration of protein within the supernatant was determined by BCA protein concentration determination kit [RTP7102, Real-Times (Beijing) Biotechnology Co., Ltd.]. The samples were then mixed with 5X SDS loading buffer before denaturation in a boiling water bath for $10 \mathrm{~min}$. Afterwards, the samples $(20 \mu \mathrm{g})$ were subjected to $10 \%$ SDS-PAGE at $100 \mathrm{~V}$. The resolved proteins were transferred to PVDF membranes on ice $(100 \mathrm{~V}, 2 \mathrm{~h})$ and blocked with 5\% skimmed milk at room temperature for $1 \mathrm{~h}$. Then, the membranes were incubated with rabbit anti-human phosphorylated (P)-STAT3 (1:1,500; ab30647; Abcam), STAT3 $(1: 1,000 ;$ ab68153; Abcam) or $\beta$-actin $(1: 5,000$; ab129348; Abcam) monoclonal primary antibodies at $4^{\circ} \mathrm{C}$ overnight. After extensive washing with PBS with Tween-20, three times for $15 \mathrm{~min}$, the membranes were incubated with goat anti-rabbit horseradish peroxidase-conjugated secondary antibody $(1: 3,000$; ab6721; Abcam) for $1 \mathrm{~h}$ at room temperature before washing with PBS with Tween-20, three times for $15 \mathrm{~min}$. Then, the membrane was developed with an ECL kit (Sigma-Aldrich; Merck KGaA) for imaging. Image Lab v3.0 software (Bio-Rad Laboratories, Inc.) was used to acquire and analyze imaging signals. The relative amounts of target proteins were normalized against $\beta$-actin.

Statistical analysis. The results were analyzed using SPSS 20.0 statistical software (IBM Corp.). The data are shown as the mean \pm SD. Multigroup measurement data were analyzed using one-way ANOVAs, followed by Student-Newman-Keuls post-hoc tests. Comparisons between two groups were carried out using the Student's t-test. Three repeats were performed for each experiment. $\mathrm{P}<0.05$ was considered to indicate a statistically significant difference.

\section{Results}

Crocin inhibits the proliferation of HCT116 cells in a dose-dependent manner and a high dose of crocin results in a lower level of proliferation. To calculate the $\mathrm{IC}_{50}$ of crocin on the proliferation of HCT116 cells, the cells were treated with $50,100,200,400,800$ or $1,600 \mu \mathrm{M}$ crocin for $48 \mathrm{~h}$ and an MTT assay was performed. These data showed that crocin inhibited the proliferation of HCT116 cells in a dose-dependent manner and the $\mathrm{IC}_{50}$ was $271.18 \pm 21.83 \mu \mathrm{M}$ (Fig. 1A). The absorbance of HCT116 cells in both the low- and high-dose groups was significantly lower than that in the control group $(\mathrm{P}<0.05$ for both), and that in low-dose group was significantly higher than that in high-dose group after $72 \mathrm{~h}(\mathrm{P}<0.05$; Fig. 1B). The results suggested that crocin inhibited the proliferation of HCT116 cells in a dose-dependent manner, with higher doses of crocin resulting in lower levels of proliferation.

Crocin does not affect the invasion ability of HCT116 cells. To evaluate the invasion of HCT116 cells, Transwell assays were carried out. These data showed that number of invasive cells in either the high-dose crocin group or the low-dose crocin group was not different from that of the control group ( $>>0.05$; Fig. 2). These results indicated that crocin did not affect the invasive capabilities of HCT116 cells.

Crocin increases the apoptosis of HCT116 cells and a high dose of crocin leads to a higher level of apoptosis. To examine the effect of crocin on the apoptosis of HCT116 cells, flow cytometry and Hoechst/PI staining were carried out after treatment with high-dose and low-dose crocin for $72 \mathrm{~h}$. These data showed that both high- and low-dose crocin treatment induced significant apoptosis of HCT116 cells, and the apoptotic rate in the low-dose group was significantly lower than that in the high-dose group $(\mathrm{P}<0.05$; Fig. 3A). Hoechst/PI staining showed a similar trend to the flow cytometry data (Fig. 3B). The results indicate that crocin increased the apoptosis of HCT116 cells and a higher dose of crocin led to a higher level of apoptosis.

Crocin decreases the secretion of chemokines and inflammatory factors from HCT116 cells and a high dose of crocin causes reduced secretion of these factors. To examine how crocin influences the mRNA levels of chemokines (MIP2, IL- 8 and MCP-1) and inflammatory factors (TNF- $\alpha$, IL-6 and IL-1 $\beta)$, as well as the secretion in the culture supernatant of 
Control
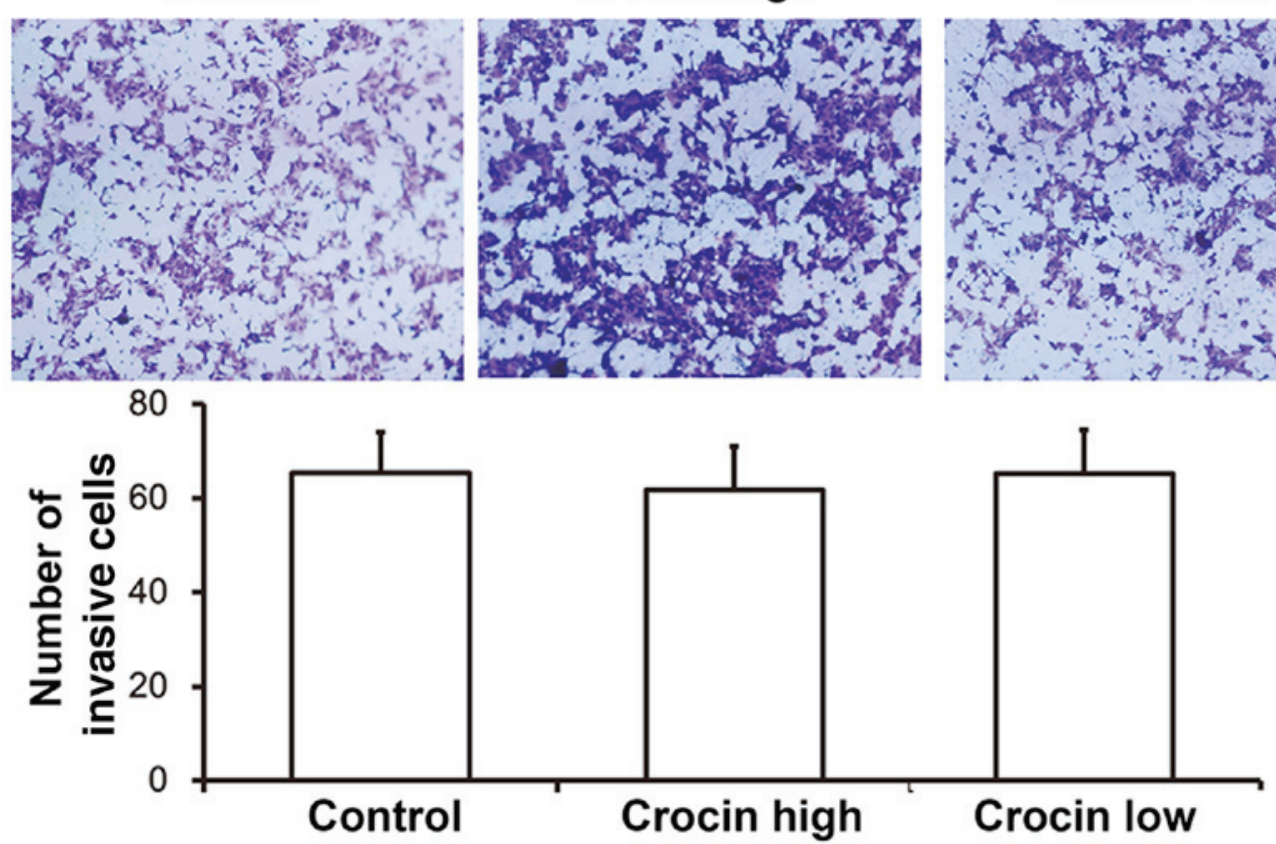

Crocin high
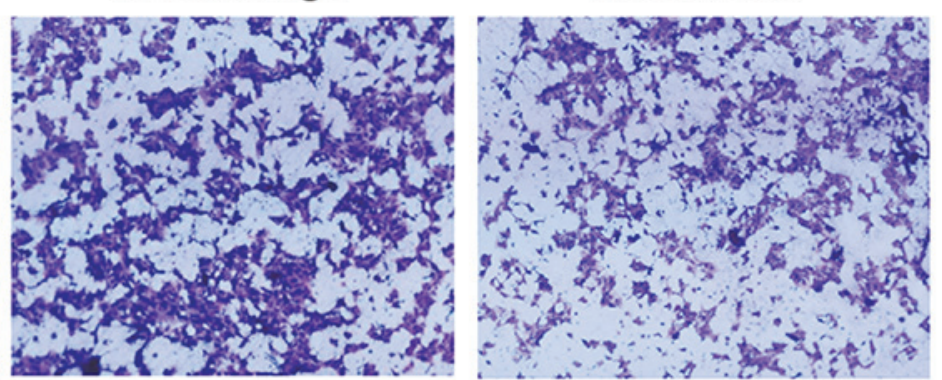

Figure 2. Effect of crocin on the invasion of HCT116 cells. A Transwell assay was used to determine the invasion ability of HCT116 cells.

these factors from HCT116 cells at $72 \mathrm{~h}$ following treatment with crocin, RT-qPCR and ELISA were employed. These data showed that the mRNA expression and secretion of MIP2, IL-8, MCP-1, TNF- $\alpha$, IL- 6 and IL- $1 \beta$ in both the high- and low-dose crocin groups were significantly lower than that in the control group $(\mathrm{P}<0.05)$, and those in the low-dose group were significantly higher than those in the high-dose group $(\mathrm{P}<0.05)$ (Fig. 4). The results suggested that crocin decreased the secretion of chemokines and inflammatory factors from HCT116 cells, and a high-dose of crocin had the most significant effect.

Crocin reduces the levels of P-STAT3, and thereby reduces the release of cytokines. The secretion of chemokines and inflammatory factors is regulated by the STAT3 signaling pathway (17). To examine the expression of proteins related to the STAT3 signaling pathway, western blotting was used. The data showed that the expression of P-STAT3 in the Stattic group was significantly reduced compared to the control group $(\mathrm{P}<0.05)$. Similarly, the expression of P-STAT3 in the high- and low-dose crocin treatment groups was also significantly lower than that in control group $(\mathrm{P}<0.05)$, and that in the low-dose group was significantly higher than that in the high-dose group $(\mathrm{P}<0.05)$ (Fig. 5). These results indicated that crocin reduces the levels of P-STAT3, and thereby reduced the release of cytokines.

\section{Discussion}

At present, surgical treatment combined with radiotherapy, chemotherapy and molecular targeted therapy, is the main treatment procedure for colorectal cancer, but the surgical cure rate and postoperative survival rate is still low $(18,19)$. Therefore, finding effective drugs to treat colorectal cancer is crucial. Crocin is reported to have anti-myocardial ischemia and anti-atherosclerotic properties, to regulate the immune system, protect the liver and gallbladder, and regulate blood lipid levels (20). In vitro experiments show that crocin has a strong cytotoxic effect on tumor cells. For example, crocin and its liposomal form can induce apoptosis in Hela and MCF-7 cells, and the liposomal form of crocin has increased cytotoxicity compared with crocin (21). Additionally, crocin inhibits the proliferation of tongue squamous cell carcinoma cells and inhibits their nucleic acid synthesis, as well as inducing apoptosis (22). Cells treated with crocin show extensive cytoplasmic vacuolar regions and cytoplasmic reduction, but the sensitivity to crocin varies between cell lines (23). Animal experiments show that crocin can reverse tumor-like pathological changes in mice and is a potential antitumor agent (24). According to a previous report, it was found that crocin may have a dose-dependent effect on tumors (25); therefore, the present study tested the effect of low- and high-dose treatments of crocin on colon cancer cells. The results showed that crocin inhibited the proliferation of HCT116 cells. After obtaining the $\mathrm{IC}_{50}$ value, the cells were treated with high $(271.18 \mu \mathrm{M})$ and low $(135.6 \mu \mathrm{M})$ doses of crocin in the following experiments. Flow cytometry showed that crocin induced apoptosis of HCT116 cells in a dose dependent manner. This further demonstrated that crocin has an inhibitory effect on the survival of colon cancer cells.

Chemokines and inflammatory factors released by colon cancer cells are some of the important factors affecting the progression of the disease (26). In the present study, the quantity of common inflammatory factors (IL-6, IL-1 $\beta$ and TNF- $\alpha$ ) (27) and chemokines (MIP2, MCP-1 and IL-8) $(28,29)$ secreted by HCT116 cells was examined. MIP2, MCP-1 and IL- 8 are reported to promote the aggregation of neutrophils to tumor sites, and thus are deemed biomarkers for the chemotactic and metastatic capability of cells (30-33). As stimulating factors, IL-6, IL-1 $\beta$ and TNF- $\alpha$ further promote the transformation 
A

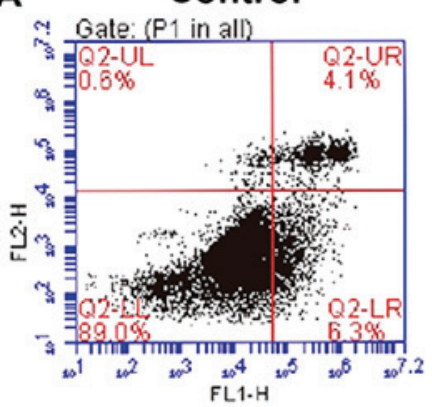

Crocin high

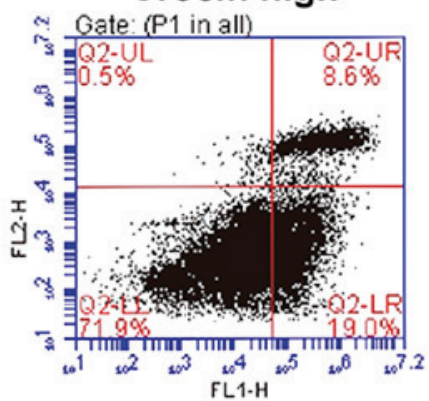

Crocin low

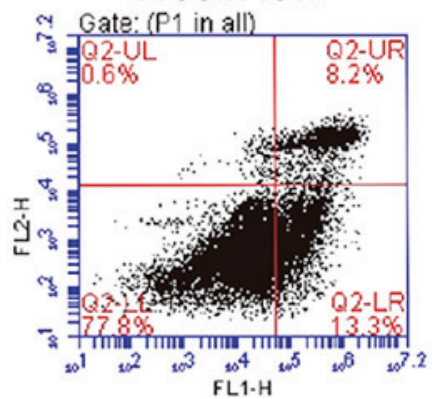

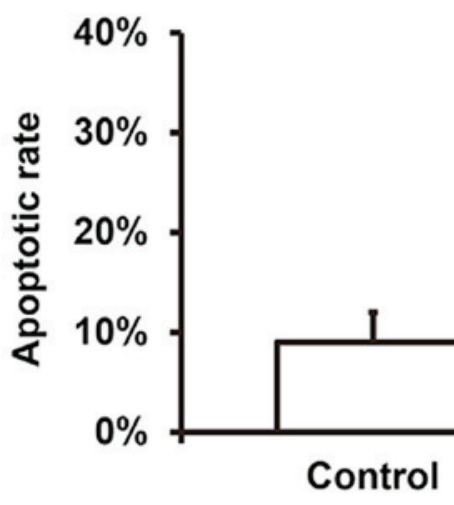

B
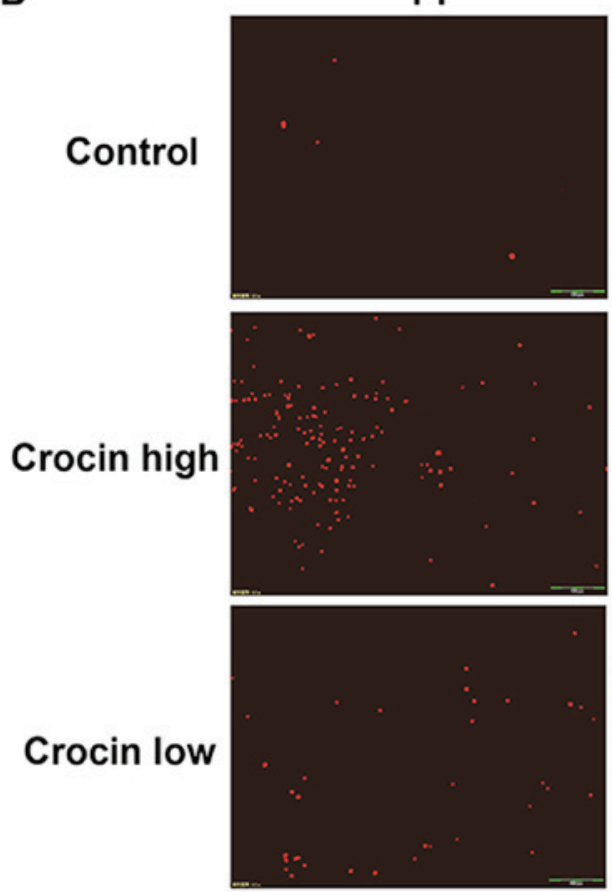

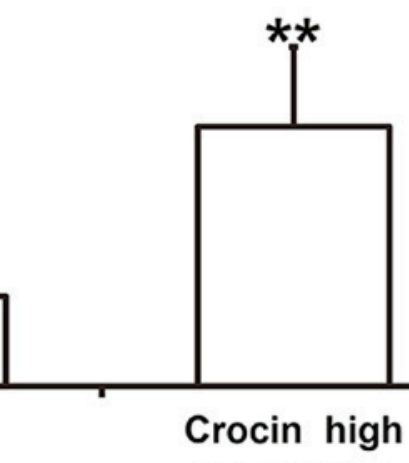

HOECHST
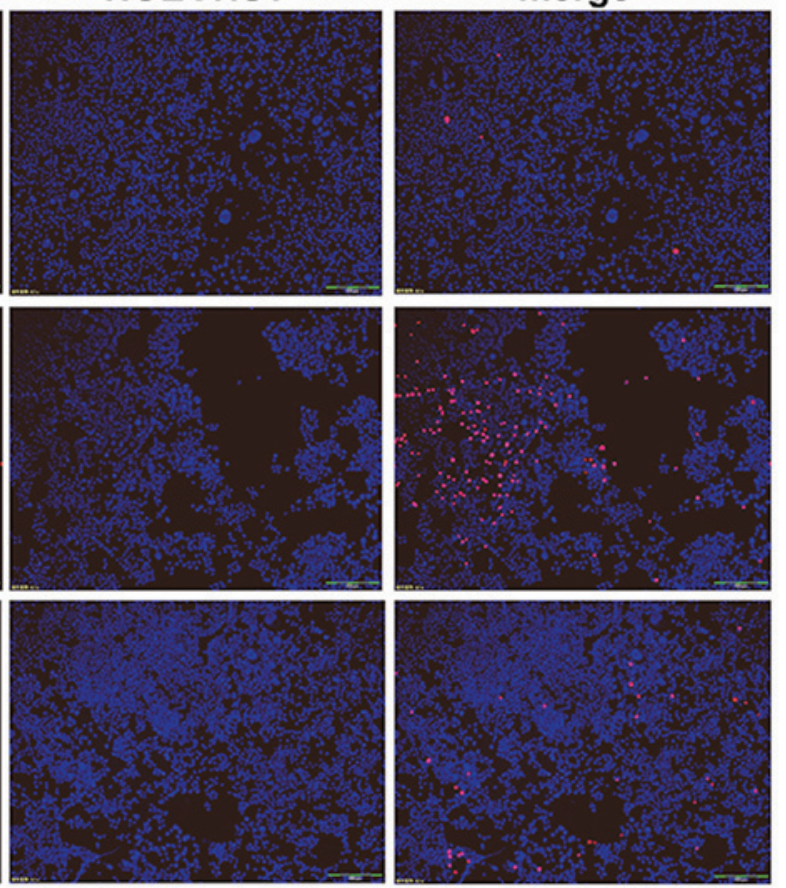

Figure 3. Apoptosis of HCT116 cells in the crocin high- and low-dose groups. (A) Apoptotic rate of HCT116 cells determined by flow cytometry. (B) Images of HCT116 cells double-stained with Hoechst/PI. Magnification, $\mathrm{x} 100 .{ }^{*} \mathrm{P}<0.05,{ }^{* *} \mathrm{P}<0.01$ vs. the control group; ${ }^{*} \mathrm{P}<0.05$ vs. crocin high. $\mathrm{PI}$, propidium iodide.

from inflammation to colon cancer $(12,13)$. The results showed that crocin treatment reduced the levels of MIP2, MCP-1, IL-8, IL-6, IL- $1 \beta$ and TNF- $\alpha$ in the supernatant from cultured HCT116 cells. It has been demonstrated that activation of the STAT3 signaling pathway is important for cell proliferation, migration and survival, and can also lead to the release of chemokines and inflammatory factors (17). The results of the present study showed that crocin treatment reduced the expression of P-STAT3 in HCT116 cells, suggesting that crocin may affect the proliferation and apoptosis of HCT116 cells and that crocin may also affect the release of chemokines and inflammatory factors from HCT116 cells, by inhibiting the activity of the STAT3 signaling pathway. A limitation of the present study is that only one cell line was used. Further studies should extend the number of cell lines used to confirm these observations.

In conclusion, the present study demonstrated that crocin has pharmacological effects against the pathological behavior of colon cancer cells, and its mechanism of action may be related to the STAT3 signaling pathway. However, the exact mechanism of action still requires further investigation. 

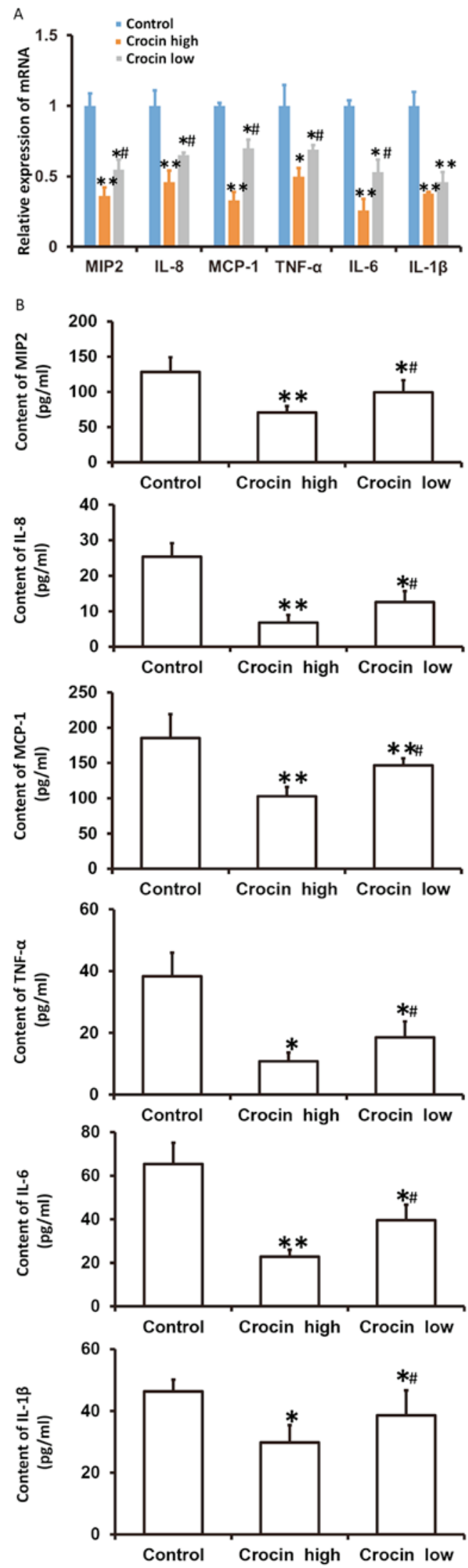

Figure 4. Expression of chemokines and inflammatory factors. (A) mRNA expression and (B) secretion of chemokines (MIP2, IL-8 and MCP-1) and inflammatory factors (TNF- $\alpha$, IL- 6 and IL-1 $\beta$ ) by HCT116 cells in the crocin high- and low-dose groups. Reverse transcription-quantitative PCR was used to measure intracellular mRNA expression and ELISA was performed to determine the content of the factors in supernatant of HCT116 cells. ${ }^{*} \mathrm{P}<0.05,{ }^{* *} \mathrm{P}<0.01$ vs. the control group; ${ }^{~} \mathrm{P}<0.05$ vs. crocin high. IL, interleukin; MIP, macrophage inflammatory protein; MCP, monocyte chemoattractant protein; TNF, tumor necrosis factor.

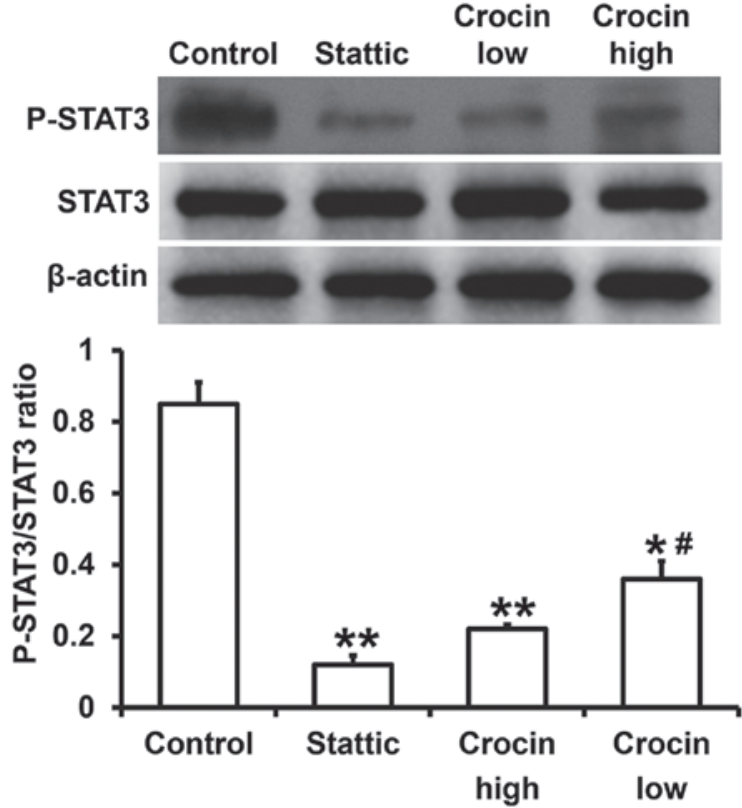

Figure 5. Expression of proteins related to the STAT3 signaling pathway in HCT116 cells of the Stattic, crocin high-dose and low-dose groups. Stattic was reported to inhibit the activity of the STAT3 signaling pathway. Western blotting was used to determine the expression of P-STAT3 and STAT3 and the ratio of P-STAT3/STAT3 was calculated and compared. ${ }^{*} \mathrm{P}<0.05$, ${ }^{* *} \mathrm{P}<0.01$ vs. the control group; ${ }^{*} \mathrm{P}<0.05$ vs. crocin high. $\mathrm{P}$, phosphorylated.

\section{Acknowledgements}

Not applicable.

\section{Funding}

No funding was received.

\section{Availability of data and materials}

The datasets used and/or analyzed during the current study are available from the corresponding author on reasonable request.

\section{Authors' contributions}

The final version of the manuscript has been read and approved by all authors, and each author states that the manuscript represents honest work. JW and TS collaborated to design the study. JW, YK and TS were responsible for performing experiments. JW and TS analyzed the data. All authors collaborated to interpret results and develop the manuscript.

\section{Ethics approval and consent to participate}

Not applicable.

\section{Patient consent for publication}

Not applicable.

\section{Competing interests}

The authors declare that they have no competing interests. 


\section{References}

1. Lee IA, Lee JH, Baek NI and Kim DH: Antihyperlipidemic effect of crocin isolated from the fructus of Gardenia jasminoides and its metabolite Crocetin. Biol Pharm Bull 28: 2106-2110, 2005.

2. Abe K and Saito H: Effects of saffron extract and its constituent crocin on learning behaviour and long-term potentiation. Phytother Res 14: 149-152, 2000.

3. Sun Y, Xu HJ, Zhao YX, Wang LZ, Sun LR, Wang Z and Sun XF: Crocin exhibits antitumor effects on human leukemia HL-60 cells in vitro and in vivo. Evid Based Complement Alternat Med 2013: 690164, 2013.

4. He SY, Qian ZY, Tang FT, Wen N, Xu GL and Sheng L: Effect of crocin on experimental atherosclerosis in quails and its mechanisms. Life Sci 77: 907-921, 2005.

5. Nair SC, Kurumboor SK and Hasegawa JH: Saffron chemoprevention in biology and medicine: A review. Cancer Biother 10: 257-264, 1995.

6. Hsu JD, Chou FP, Lee MJ, Chiang HC, Lin YL, Shiow SJ and Wang CJ: Suppression of the TPA-induced expression of nuclear-protooncogenes in mouse epidermis by crocetin via antioxidant activity. Anticancer Res 19: 4221-4227, 1999.

7. Li K, Li Y, MaZ and Zhao J: Crocin exerts anti-inflammatory and anti-catabolic effects on rat intervertebral discs by suppressing the activation of JNK. Int J Mol Med 36: 1291-1299, 2015.

8. Tamaddonfard E, Farshid AA, Eghdami K, Samadi F and Erfanparast A: Comparison of the effects of crocin, safranal and diclofenac on local inflammation and inflammatory pain responses induced by carrageenan in rats. Pharmacol Rep 65: 1272-1280, 2013.

9. Chen W, Zheng R, Baade PD, Zhang S, Zeng H, Bray F, Jemal A, Yu XQ and He J: Cancer statistics in China, 2015. CA Cancer J Clin 66: 115-132, 2016.

10. Thosani N, Guha S and Singh H: Colonoscopy and colorectal cancer incidence and mortality. Gastroenterol Clin North Am 42: 619-637, 2013.

11. Wang $\mathrm{K}$ and Karin $\mathrm{M}$ : Tumor-elicited inflammation and colorectal cancer. Adv Cancer Res 128: 173-196, 2015.

12. Chung KS, Cheon SY, Roh SS, Lee M and An $\mathrm{HJ}$ : Chemopreventive effect of aster glehni on inflammation-induced colorectal carcinogenesis in mice. Nutrients 10: pii: E202, 2018.

13. Ray AL, Berggren KL, Restrepo Cruz S, Gan GN and Beswick EJ: Inhibition of MK2 suppresses IL-1 $\beta$, IL-6, and TNF- $\alpha$-dependent colorectal cancer growth. Int J Cancer 142: 1702-1711, 2018.

14. Li CY, Huang WF, Wang QL, Wang F, Cai E, Hu B, Du JC, Wang J, Chen R, Cai XJ, et al: Crocetin induces cytotoxicity in colon cancer cells via p53-independent mechanisms. Asian Pac J Cancer Prev 13: 3757-3761, 2012.

15. Arocho A, Chen B, Ladanyi M and Pan Q: Validation of the 2-DeltaDeltaCt calculation as an alternate method of data analysis for quantitative PCR of BCR-ABL P210 transcripts. Diagn Mol Pathol 15: 56-61, 2006.

16. Livak KJ and Schmittgen TD: Analysis of relative gene expression data using real-time quantitative PCR and the 2(-Delta Delta C(T)) method. Methods 25: 402-408, 2001.

17. Kim WH, An HJ, Kim JY, Gwon MG, Gu H, Lee SJ, Park JY, Park KD, Han SM, Kim MK and Park KK: Apamin inhibits TNF- $\alpha$ - and IFN- $\gamma$-induced inflammatory cytokines and chemokines via suppressions of NF- $\kappa B$ signaling pathway and STAT in human keratinocytes. Pharmacol Rep 69: 1030-1035, 2017.

18. Edwards BK, Ward E, Kohler BA, Eheman C, Zauber AG, Anderson RN, Jemal A, Schymura MJ, Lansdorp-Vogelaar I, Seeff LC, et al: Annual report to the nation on the status of cancer, 1975-2006, featuring colorectal cancer trends and impact of interventions (risk factors, screening, and treatment) to reduce future rates. Cancer 116: 544-573, 2010.
19. Franko J, Shi Q, Goldman CD, Pockaj BA, Nelson GD, Goldberg RM, Pitot HC, Grothey A, Alberts SR and Sargent DJ: Treatment of colorectal peritoneal carcinomatosis with systemic chemotherapy: A pooled analysis of north central cancer treatment group phase III trials N9741 and N9841. J Clin Oncol 30: 263-267, 2012.

20. PZ and C L: Research progress of anticancer active substances in Crocus sativus. Int J Laboratory Med 2: 140-142, 2006.

21. Mousavi SH, Moallem SA, Mehri S, Shahsavand S, Nassirli H and Malaekeh-Nikouei B: Improvement of cytotoxic and apoptogenic properties of crocin in cancer cell lines by its nanoliposomal form. Pharm Biol 49: 1039-1045, 2011.

22. Sun J, Xu XM, Ni CZ, Zhang H, Li XY, Zhang CL, Liu YR, Li SF, Zhou QZ and Zhou HM: Crocin inhibits proliferation and nucleic acid synthesis and induces apoptosis in the human tongue squamous cell carcinoma cell line Tca8113. Asian Pac J Cancer Prev 12: 2679-2683, 2011

23. Garcia-Olmo DC, Riese HH, Escribano J, Ontañón J, Fernandez JA, Atiénzar M and García-Olmo D: Effects of long-term treatment of colon adenocarcinoma with crocin, a carotenoid from saffron (Crocus sativus L.): An experimental study in the rat. Nutr Cancer 35: 120-126, 1999.

24. Magesh V, Singh JP, Selvendiran K, Ekambaram G and Sakthisekaran D: Antitumour activity of crocetin in accordance to tumor incidence, antioxidant status, drug metabolizing enzymes and histopathological studies. Mol Cell Biochem 287: 127-135, 2006

25. Huang Y, Wang S, Zhang C, Xu Z, Shen J, Du X, Zhang H, Zhang $\mathrm{K}$ and Zhang D: Experimental study of the anti-atherosclerotic effect of demethylzeylasteral. Exp Ther Med 13: 2787-2792, 2017

26. Itatani Y, Kawada K, Inamoto S, Yamamoto T, Ogawa R, Taketo MM and Sakai Y: The role of chemokines in promoting colorectal cancer invasion/metastasis. Int J Mol Sci 17: pii: E643, 2016.

27. Shen L, Zhou T, Wang J, Sang X, Lan L, Luo L and Yin Z: Daphnetin reduces endotoxin lethality in mice and decreases LPS-induced inflammation in Raw264.7 cells via suppressing JAK/STATs activation and ROS production. Inflamm Res 66: 579-589, 2017.

28. Hao C, Wu B, Hou Z, Xie Q, Liao T, Wang T and Ma D: Asiatic acid inhibits LPS-induced inflammatory response in human gingival fibroblasts. Int Immunopharmacol 50: 313-318, 2017.

29. Kim KJ, Yoon KY, Yoon HS, Oh SR and Lee BY: Brazilein suppresses inflammation through inactivation of IRAK4-NF-kB pathway in LPS-induced Raw264.7 macrophage cells. Int J Mol Sci 16: 27589-27598, 2015.

30. Wang ZW, Wang JJ, Zhang JZ, Xue ZJ, Miao J, Li L and Hu WX: Thrombolysis of deep vein thrombosis and inhibiting chemotax is of macrophage by MCP-1 blockage. Eur Rev Med Pharmacol Sci 21: 1695-1701, 2017.

31. Hol J, Wilhelmsen L and Haraldsen G: The murine IL-8 homologues KC, MIP-2, and LIX are found in endothelial cytoplasmic granules but not in Weibel-Palade bodies. J Leukoc Biol 87: 501-508, 2010.

32. Kadioglu A and Andrew PW: Susceptibility and resistance to pneumococcal disease in mice. Brief Funct Genomic Proteomic 4: 241-247, 2005.

33. Gerber J, Pohl K, Sander V, Bunkowski S and Nau R: Rifampin followed by ceftriaxone for experimental meningitis decreases lipoteichoic acid concentrations in cerebrospinal fluid and reduces neuronal damage in comparison to ceftriaxone alone. Antimicrob Agents Chemother 47: 1313-1317, 2003.

This work is licensed under a Creative Commons Attribution-NonCommercial-NoDerivatives 4.0 International (CC BY-NC-ND 4.0) License. 